\title{
O desenvolvimento urbano de Juiz de Fora/MG e suas possíveis conexões ambientais
}

\author{
The urban development of Juiz de Fora/MG and its possible environmental connections \\ El desarrollo urbano de Juiz de Fora/MG y sus posibles conexiones ambientales
}

Recebido: 19/01/2022 | Revisado: 27/01/2022 | Aceito: 27/01/2022 | Publicado: 29/01/2022

\author{
Karla Carvalho de Almeida \\ ORCID: https://orcid.org/0000-0003-2425-4382 \\ Universidade Federal de Juiz de Fora, Brasil \\ E-mail: karla.almeids@ arquitetura.ufff.br \\ Karina Machado de Castro Simão \\ ORCID: https://orcid.org/0000-0002-8582-4177 \\ Pontifícia Universidade Católica de Minas Gerais, Brasil \\ E-mail: karina.machado.simao@gmail.com
}

\begin{abstract}
Resumo
Juiz de Fora, em Minas Gerais, desenvolveu importante papel no trânsito de minerais preciosos entre Ouro Preto e Rio de Janeiro durante o século XVIII. Esse trajeto determinou o princípio da cidade e o seu desenvolvimento, sendo guiados pelas margens do Rio Paraibuna, que perpassa por toda a sua extensão urbana e, atualmente, se encontra altamente poluído e vem perdendo seu significado histórico e de lazer perante a população. Qual o papel do rio no desenvolvimento da cidade e a sua importância diante dos moradores? O objetivo do trabalho consiste em analisar a evolução da ocupação da cidade e a função do rio na memória social local. Os objetivos específicos se dão pela proposta projetual de intervenção como resposta à problemática apresentada. Como metodologia, foi implementada pesquisa documental acerca do desenvolvimento urbano de Juiz de Fora, com embasamento na Escola Inglesa de Morfologia Urbana de Conzen (1998); e posteriores propostas de intervenção ambiental no trecho estudado. Os resultados consistem na descrição do processo de ocupação urbana no recorte de estudo, e na proposta de implementação de corredor ecológico ao longo do trajeto do rio como forma de resgate da historicidade e de ressignificação. $\mathrm{O}$ trabalho ressalta a importância do eixo Paraibuna no recorte de estudo como vetor de desenvolvimento urbano da cidade e seu potencial ecológico e de lazer para a população.
\end{abstract}

Palavras-chave: Morfologia urbana; Desenvolvimento urbano; Rios urbanos; Infraestrutura verde.

\begin{abstract}
Juiz de Fora, in Minas Gerais, played an important role in the transit of precious minerals between Ouro Preto and Rio de Janeiro during the 18th century. This path determined the beginning of the city and its development, being guided by the banks of the Paraibuna River, which runs through its entire urban extension and, currently, is highly polluted and has been losing its historical and leisure significance for the population. What is the role of the river in the development of the city and its importance for the residents? The objective of the work is to analyze the evolution of the occupation of the city and the function of the river in the local social memory. The specific objectives are given by the intervention project proposal as a response to the presented problem. As a methodology, documental research was implemented on the urban development of Juiz de Fora, based on the English School of Urban Morphology in Conzen (1998); and subsequent proposals for environmental intervention in the studied stretch. The results consist of the description of the urban occupation process in the study clipping, and the proposal to implement an ecological corridor along the river's path as a way of rescuing historicity and resignification. The work emphasizes the importance of the Paraibuna axis in the study as a vector of urban development of the city and its ecological and leisure potential for the population.
\end{abstract}

Keywords: Urban morphology; Urban development; Urban rivers; Green infrastructure.

\section{Resumen}

Juiz de Fora, en Minas Gerais, jugó un papel importante en el tránsito de minerales preciosos entre Ouro Preto y Río de Janeiro durante el siglo XVIII. Este camino marcó el inicio de la ciudad y su desarrollo, siendo guiado por la ribera del río Paraibuna, que recorre toda su extensión urbana y, en la actualidad, se encuentra altamente contaminado y ha ido perdiendo su significado histórico y de ocio para la población. ¿Cuál es el papel del río en el desarrollo de la ciudad y su importancia para los habitantes? El objetivo del trabajo es analizar la evolución de la ocupación de la ciudad y la función del río en la memoria social local. Los objetivos específicos vienen dados por la propuesta del proyecto de intervención como respuesta a la problemática planteada. Como metodología, se implementó una investigación documental sobre el desarrollo urbano de Juiz de Fora, con base en la Escuela Inglesa de Morfología Urbana de Conzen (1998); y posteriores propuestas de intervención ambiental en el tramo estudiado. Los resultados consisten en la descripción del proceso de ocupación urbana en el recorte de estudio, y la propuesta de implementación de un corredor ecológico a lo largo del curso del río como forma de rescate de la historicidad y resignificación. El trabajo destaca la 
importancia del eje Paraibuna en el estudio como vector de desarrollo urbano de la ciudad y su potencial ecológico y de ocio para la población.

Palabras clave: Morfología urbana; Desarrollo urbano; Ríos urbanos; Infraestructura verde.

\section{Introdução}

Apenas 6,5\% dos rios brasileiros apresentam boa qualidade da água, segundo relatório divulgado pela ONG SOS Mata Atlântica (Cardim \& Tunes, 2019). Juiz de Fora faz parte da estatística de rios com qualidade da água considerada insatisfatória. A cidade de Minas Gerais fez parte do trajeto que transitava minerais preciosos, especialmente ouro, entre Ouro Preto e Rio de Janeiro e sua história teve início no século XVIII. Seu vetor de desenvolvimento urbano consiste no Rio Paraibuna, que guiou os bandeirantes e margeou as primeiras construções da região. O rio, por sua vez, vem se degradando ao longo do tempo devido aos dejetos da população que são ali despejados e, consequentemente, vem perdendo seu significado na memória social dos moradores locais.

Juiz de Fora é uma cidade com área de 1.476 quilômetros quadrados, população aproximada de 573.285 pessoas e está a 678 metros do nível do mar (Prefeitura de Juiz de Fora, 2017). O recorte de estudo se limita por toda a cidade.

Qual o papel do rio no desenvolvimento da cidade e a sua importância diante dos moradores? O objetivo do trabalho consiste em investigar o processo de desenvolvimento urbano de Juiz de Fora, e seus impactos na estrutura físico-ambiental e na percepção da população acerca do trecho.

Os objetivos específicos consistem na análise da relação da população com o Rio Paraibuna no recorte de estudo e na proposta de diretrizes que buscam a implementação de reflorestamento e a ressignificação do rio como corredor ecológico. Além disso, tem como embasamento teórico o estudo de metodologias da escola inglesa de morfologia urbana de Conzen (1998).

\section{Metodologia}

A fim de alcançar os objetivos mencionados, foi utilizada uma análise qualitativa (Sampieri et al., 2013), baseada em pesquisas bibliográficas e documentais. De acordo com os autores, esse tipo de abordagem é utilizado para análise de fenômenos sociais, relacionados a um determinado tempo, local e cultura. Atua como respaldo de temas que não podem ser quantificados. Associado ao trabalho de campo, embasou a pesquisa sobre a ocupação urbana do recorte de estudo e sobre a percepção ambiental da população.

Dessa forma, foi desenvolvida, primeiramente, revisão integrativa acerca de conceitos relacionados à problemática como cunhas verdes, efeito de borda e corredores ecológicos - baseados em Oliveira (2020), Tabanez et al (1997) e Seoane (2010).

Paralelamente, foi feita pesquisa descritiva documental (Gil, 2008) - que caracteriza-se pela descrição de determinado fenômeno, no caso, a ocupação urbana - sobre as características geofísicas de Juiz de Fora e o desenvolvimento urbano da cidade, de acordo com a Escola Inglesa de Morfologia Urbana de Conzen (1998). Seguindo a teoria de Conzen, a pesquisa foi baseada nas transformações da forma urbana ao longo do tempo - através da visão tripartite, que consiste no estudo do plano urbano, do tecido urbano e no padrão de uso e ocupação das edificações -, a fim de estabelecer uma teoria sobre a construção da cidade (Pereira Costa \& Gimmler Netto, 2015).

Posteriormente, foram desenvolvidas pesquisas de campo e entrevistas com moradores locais sobre a percepção ambiental, baseada na teoria de Lynch (2006), em que os usuários descrevem como percebem os elementos constituintes dessa região: caminhos, limites, setores, pontos nodais e marcos. O objetivo é entender o significado do rio no trecho analisado.

Por fim, foram propostas as diretrizes projetuais como solução urbana para as problemáticas apresentadas, unindo o diagnóstico qualitativo da área e os conceitos científicos abordados anteriormente. 
O artigo se inicia com uma introdução sobre a localização e a breve descrição do recorte de estudo. A seguir, é apresentada a estrutura físico ambiental da cidade e o desenvolvimento urbano do recorte de estudo. Posteriormente, baseado em entrevistas realizadas com a população local, é apresentado o mapa de percepção ambiental da área em estudo. Por fim, são apontadas diretrizes projetuais que respondam à demanda populacional pela ressignificação do Rio Paraibuna e que estejam de acordo com a ocupação urbana ali desenvolvida.

\section{Resultados e Discussão}

\subsection{Características geofísicas de Juiz de Fora}

A cidade está contida na bacia hidrográfica do Médio Paraibuna, pertencente à bacia do rio Paraíba do Sul (CESAMA, 2019), que abrange quatro rios principais (Rio Preto, Rio do Peixe, Rio Paraibuna e Rio Cágado) e diversos outros rios menores.

A Figura 1 demonstra a localização do recorte de estudo.

Figura 1: Juiz de Fora, Minas Gerais.

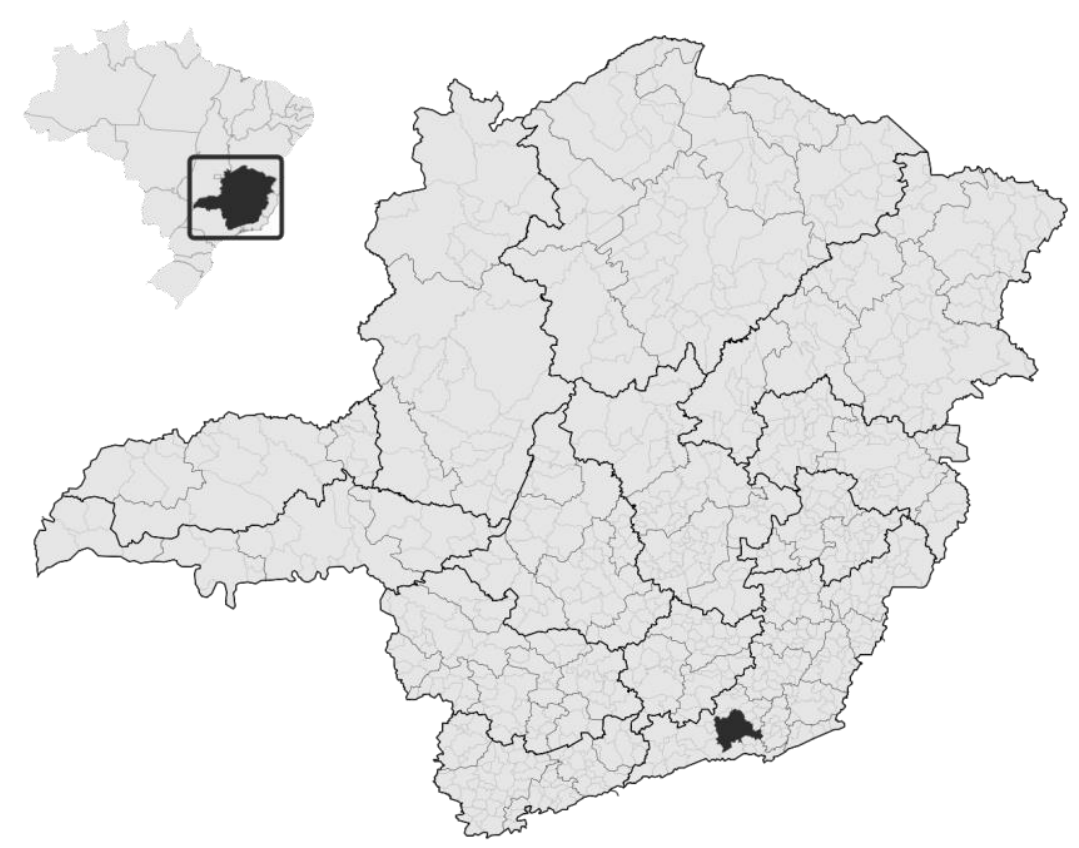

Fonte: QGis, adaptado pela autora.

Seu solo é classificado majoritariamente como latossolo: altamente intemperizado, mineral e homogêneo; com textura variando de médio a muito argiloso; é profundo e bem drenado; e possui acidez, requerendo manejo e adubação adequados (Prefeitura de Juiz de Fora, 2014).

A bacia hidrográfica abundante e o solo argiloso denotam relativa facilidade em crescimento arbóreo, desde que seja adotado o paisagismo adequado, com espécies nativas (Carvalho et al., 2019).

A cidade possui cunhas verdes em seu entorno, remanescentes da Mata Atlântica presente na região. O conceito de cunhas verdes consiste em florestas que circundam o tecido urbano e que penetram na cidade, afunilando sua área à medida em que o fazem. Algumas de suas vantagens para a cidade são a maior absorção e filtragem da água da chuva, a criação de ecossistemas, o crescimento populacional da fauna e da flora, a diminuição da temperatura e regulação da umidade local benefícios conhecidos como serviços ecossistêmicos. Além das melhorias ambientais, as cunhas verdes promovem espaços de lazer e convivência à população quando integradas à cidade (Oliveira, 2020). 
Apesar das vantagens das cunhas verdes, algumas massas arbóreas apresentam efeito de borda. Quando um fragmento arbóreo é imerso em ecossistemas não naturais como plantações, pasto ou centros urbanos, a região da margem desse fragmento sofre uma alteração de composição e/ou abundância das espécies, tornando-as vulneráveis em relação a ações externas - chamado efeito de borda (Forman e Godron, 1986). O fenômeno também pode ser definido como a influência que o meio externo exerce sobre a margem da massa florestal (Tabanez et al., 1997). A Figura 2 demonstra o mapeamento do centro urbano, das cunhas existentes em seu entorno, do Rio Paraibuna e do possível efeito de borda identificado.

Figura 2: Mapeamento da cidade de Juiz de Fora, Minas Gerais.

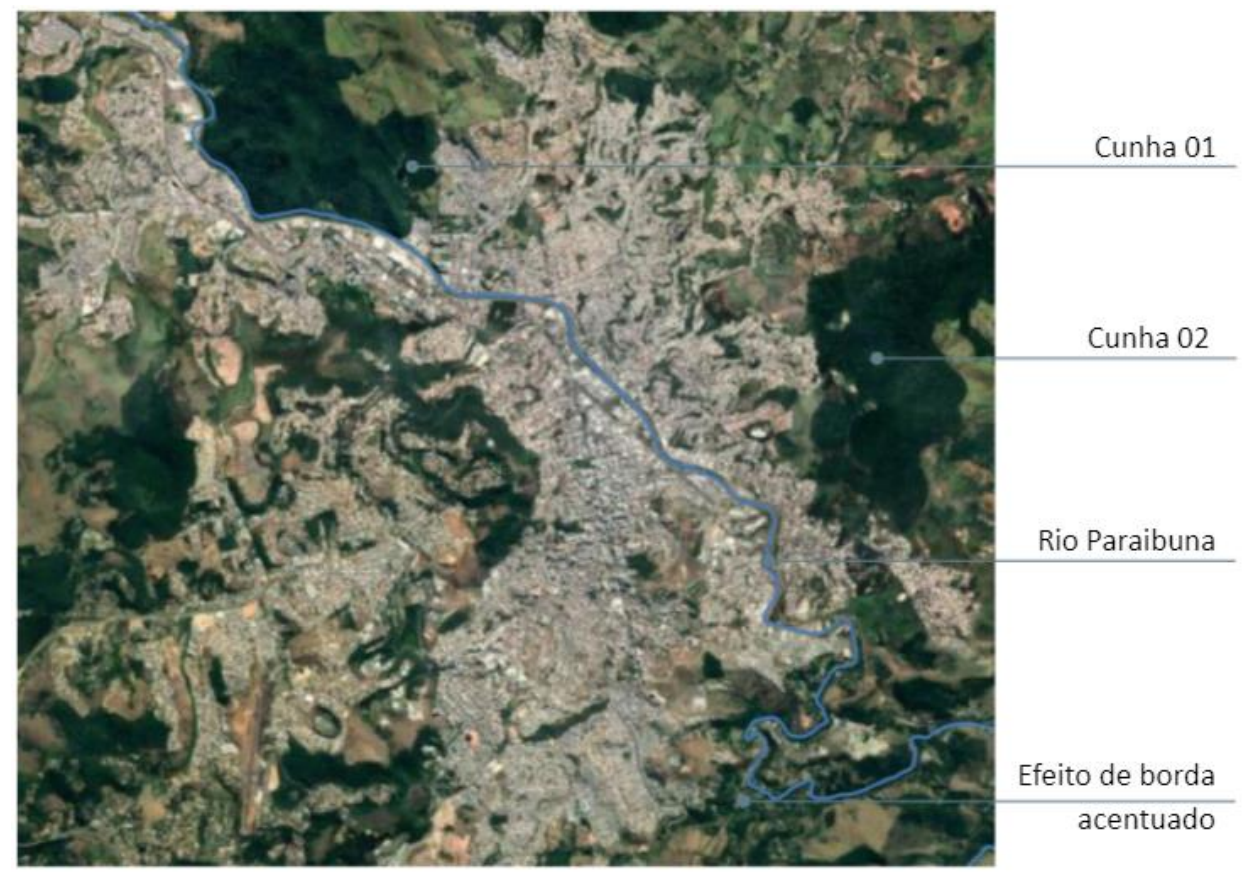

Fonte: QGis, adaptado pela autora (2021).

\subsection{O desenvolvimento urbano de Juiz de Fora}

Inicialmente, havia o espaço natural, anteriormente à descoberta da Zona da Mata pelos bandeirantes. Antes da chegada de colonizadores na região, Juiz de Fora estava contida na Mata Atlântica, onde os morros e vales abrangiam sua vegetação de grande porte. Dessa forma, foi intitulada Zona da Mata e habitada pelas populações indígenas denominadas Tupi. Uma abundante rede fluvial esculpia seu relevo, em direção ao Oceânico Atlântico, sendo o Rio Paraibuna um dos destaques dessa rede - e de onde se originou a cidade em questão (Barbosa, 2013).

Com a chegada de colonizadores no país, grupos de bandeirantes organizaram expedições por todo o interior em busca de minerais preciosos, devido ao interesse da metrópole na exploração de tais recursos. Após encontrar ouro em Minas Gerais, por volta de 1693, foi iniciada uma intensa migração para a região (Botti \& Oliveira, 1994).

O percurso aberto até a região foi denominado Caminho Velho (figura 3), que conectava os litorais fluminense e paulista até o interior de Minas Gerais. Tal trajeto somava cerca de 630 quilômetros por terra e, por contornar a região da mata, não era interesse da coroa explorá-lo devido à sua barreira natural impedir o contrabando - em que indígenas, animais e outros perigos inibiam a ação de exploradores (Dilly, 2004). 
Figura 3: Caminho Velho.

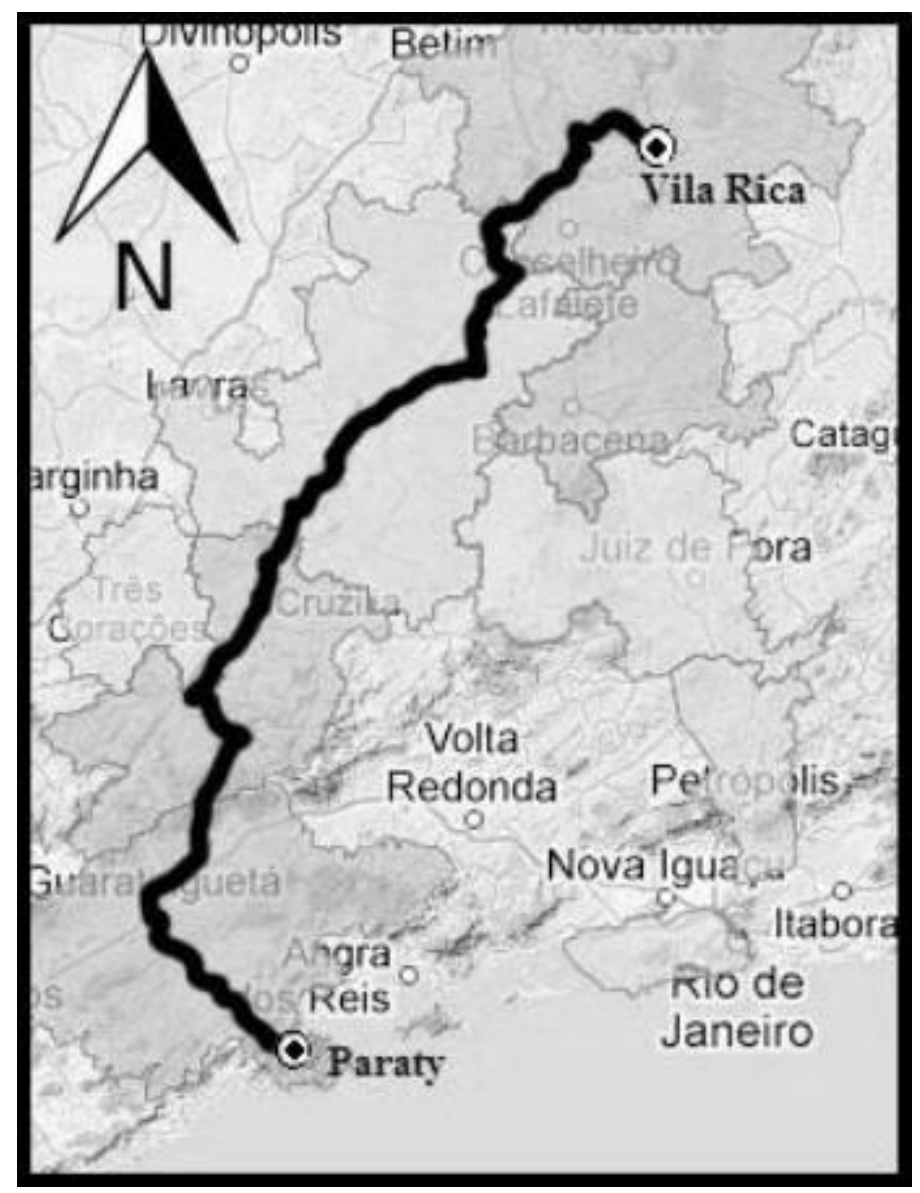

Fonte: Barbosa (2013).

Em 1698, autoridades da capitania do Rio de Janeiro solicitaram à Coroa a abertura de uma via mais segura e proveitosa. Dessa forma, o trabalho de abertura do Caminho Novo - liderado pelo bandeirante Garcia Paes Leme - foi iniciado em 1699, e inaugurado em 1707. Quase retilíneo, o caminho ligava o Porto do Rio de Janeiro à Vila Rica (Ouro Preto) em 515 quilômetros, facilitando o escoamento dos minerais extraídos do interior do estado (Barbosa, 2013), como exposto na Figura 4. 
Figura 4: Caminho Novo.

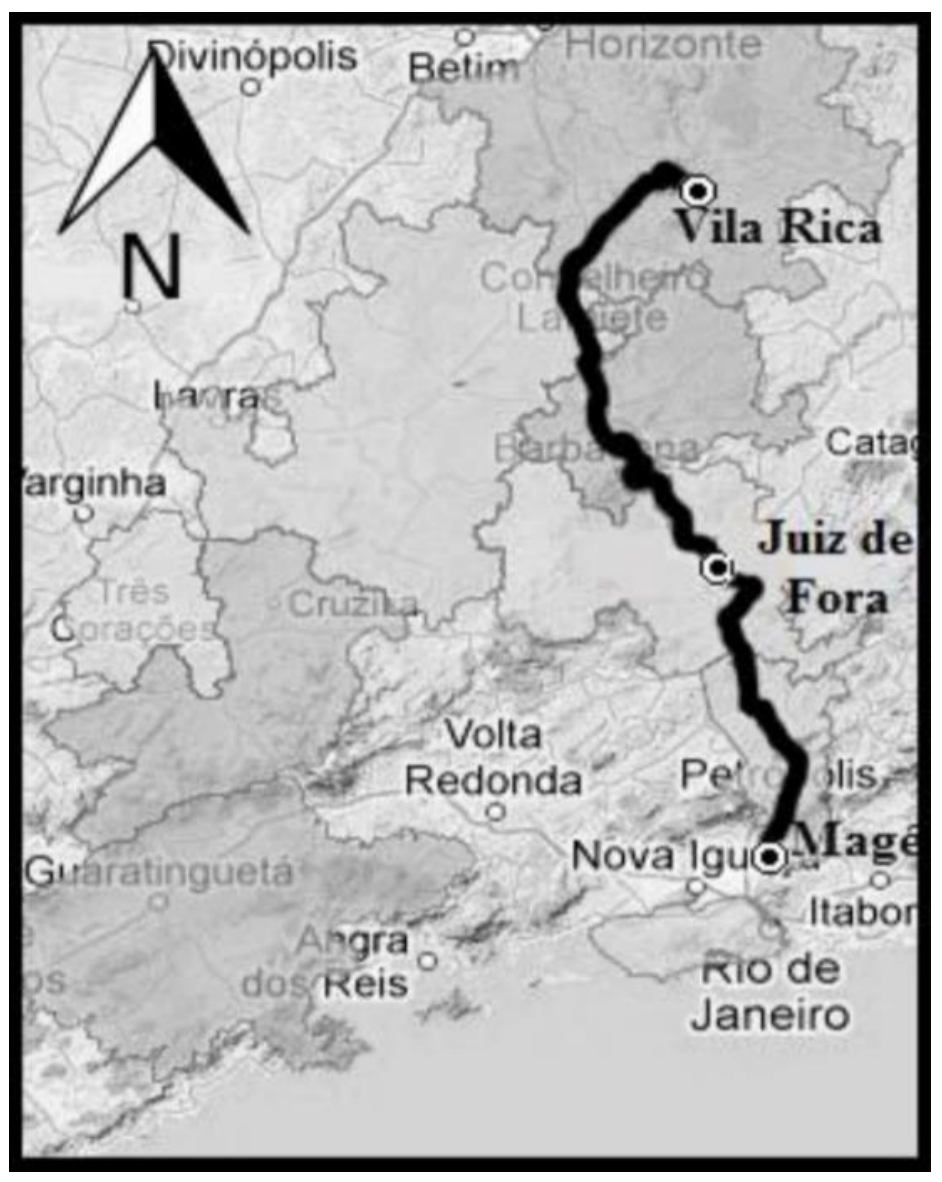

Fonte: Barbosa (2013).

Garcia Paes Leme guiou seu trajeto pelo pântano através do percurso de um rio, chamado pelos indígenas de "Para-ybuna" e pelos colonizadores de "Rio Barro" devido à sua coloração. O bandeirante construiu o trajeto pela sua margem esquerda, onde hoje estão os bairros Retiro e Santo Antônio, a Avenida Sete de Setembro, a Avenida Garibaldi Campinhos (onde se localizou a fazenda do Juiz de Fora), o bairro Vitorino Braga, Santa Terezinha, Benfica e Chapéu d’Uvas. Segundo Stehling (1979, p.102), juntamente com a missão de abrir o caminho, a coroa lhe outorgou plenos poderes para agir por onde passasse. Assim, demarcou ao longo do trajeto várias Sesmarias para si, filhos e parentes (Dilly, 2004, p. 20), ilustrado na figura seguinte. 
Figura 5: Divisão de sesmarias na região de Juiz de Fora.

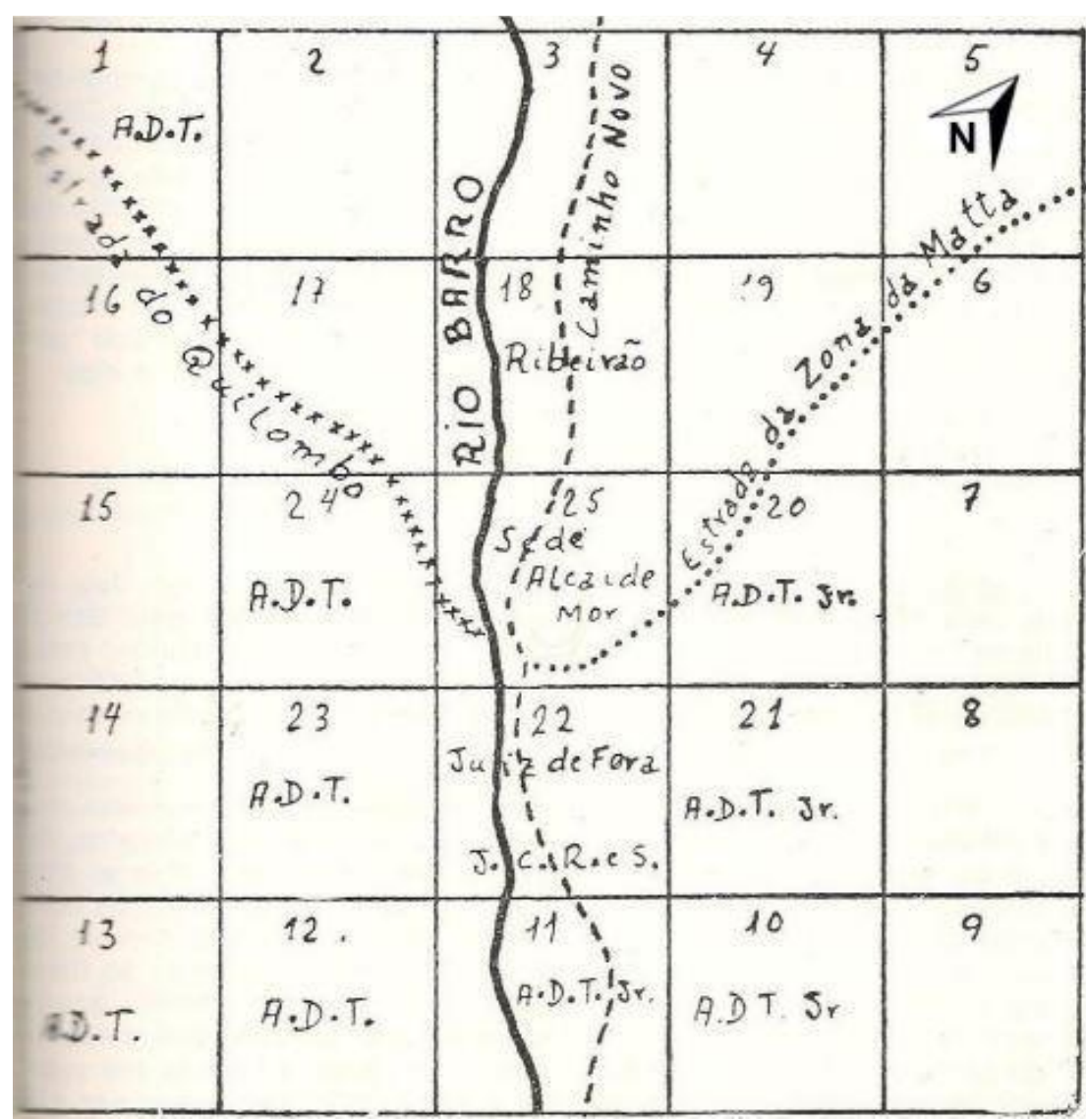

Fonte: Stehling, L. J. (1979, p. 105).

As primeiras construções surgiram com a divisão de sesmarias em 1717. O povoamento nas margens do Rio Paraibuna não ocorreu de forma acelerada, pois o governo e a população se voltavam para as zonas de exploração do ouro. Um dos maiores terrenos estabelecidos pelas cartas de sesmarias atribuía a medida de duas quadras, abrangendo ambas as margens do Rio Paraibuna. Era propriedade de João de Oliveira (Corrêa, s/d). Inicialmente, foram construídos ranchos para hospedagem de bandeirantes e algumas fazendas de famílias conhecidas como a Fazenda da Tapera de Tomá Corrêa Vasquez, a fazenda do grande terreno de João de Oliveira e a Fazenda de Luís Fortes Bustamante e Sá - juiz português que fora nomeado para o cargo como juiz de fora do Rio de Janeiro e, mais tarde, inspiraria o nome da cidade de Juiz de Fora - que foi demolida em 1946. O sobrado localizava-se no Caminho Novo, à margem esquerda do rio Paraibuna, atualmente no quarteirão formado pelas ruas Almada Horta, Barão de Juiz de Fora e Avenida Garibaldi, no Vitorino Braga. Ao longo dos anos a região onde fora erguida a sede da fazenda teve denominações diferentes como "Sesmaria do Juiz de Fora", antes da construção da sede; "Fazenda do Juiz de Fora" e "Fazenda Velha", dadas pelos habitantes da povoação que se formara na região e que viria a ser Santo Antônio do Paraibuna (Lessa, 1985).

A partir daí, a cidade começou a se desenvolver naturalmente, passando por períodos de aceleração e estagnação (Geraldo, 2014). As figuras seguintes (6 e 7) mostram o período em que cada rua do centro da cidade foi construída e a evolução da ocupação urbana, respectivamente. 
Figura 6: Construção das principais ruas do centro da cidade.

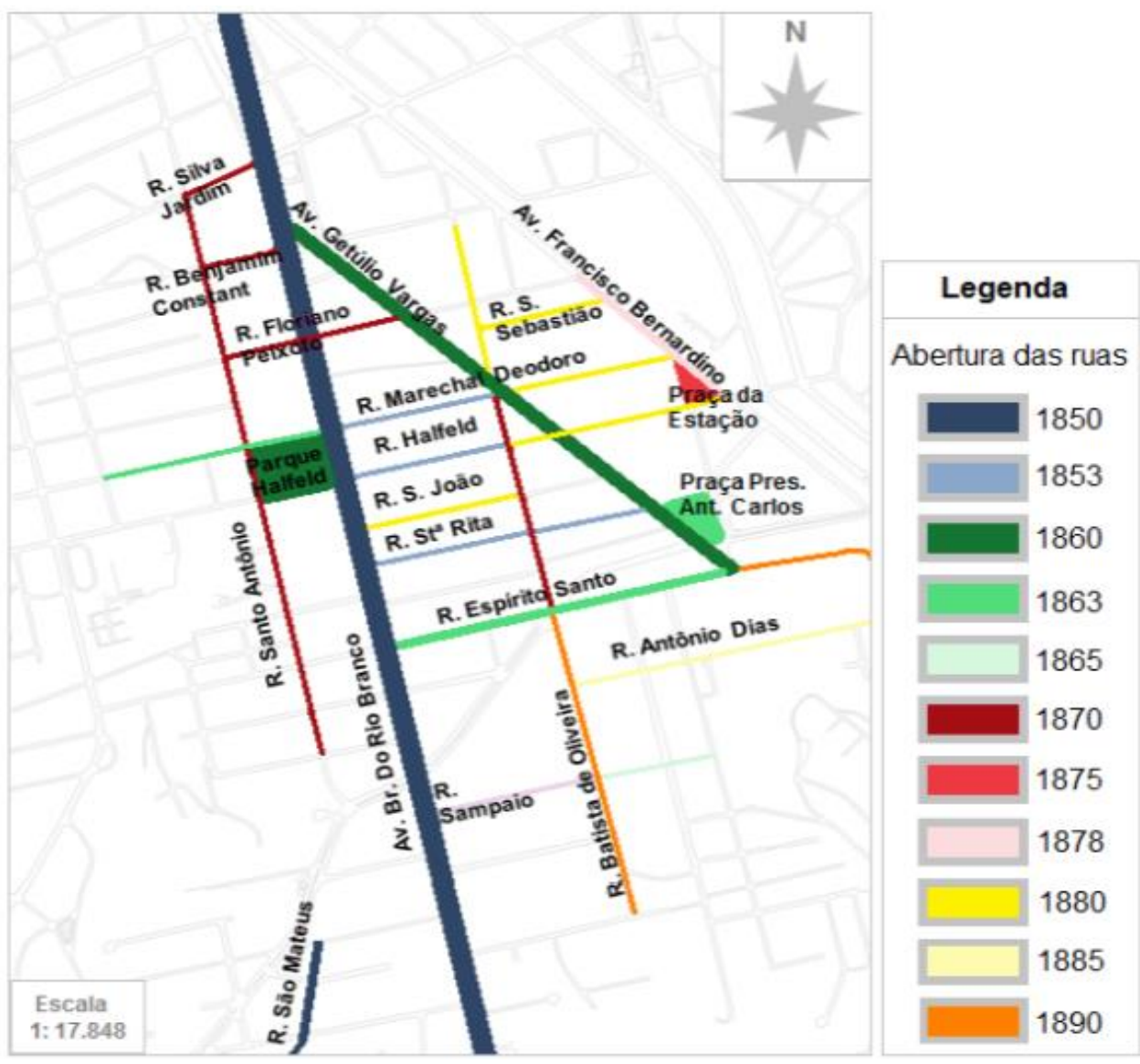

Fonte: Oliveira (2004). 
Figura 7: Evolução da ocupação urbana.

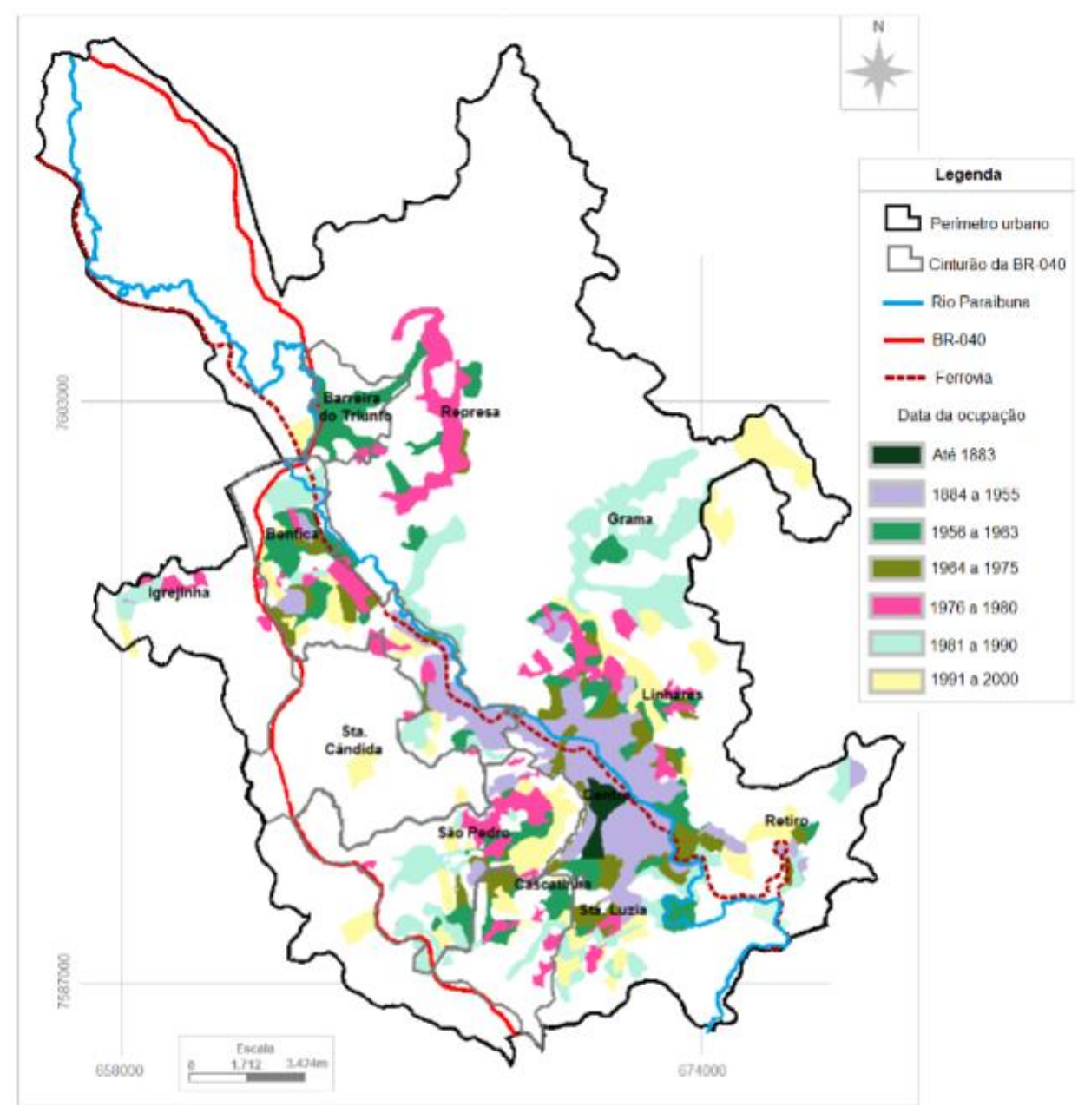

Fonte: Oliveira (2004).

Dessa forma, a evolução da ocupação urbana na cidade indica que o protagonista para o surgimento de Juiz de Fora consiste no Rio Paraibuna que, através das suas margens, guiou o trajeto de minerais preciosos e as primeiras construções da região - tornando-se essencial sua preservação para a memória social dos moradores.

\subsection{Percepção Ambiental}

Como forma de analisar a percepção dos moradores e trabalhadores da região sobre o recorte de estudo, foi utilizada a metodologia baseada em Lynch (2006). Através de entrevistas, os usuários descrevem como percebem os elementos constituintes dessa região: caminhos, limites, setores, pontos nodais e marcos (Lynch, 2006).

Nas entrevistas realizadas com feirantes e moradores do eixo central da Avenida Brasil e do Rio Paraibuna foram destacadas a poluição visual e olfativa que o rio representa na rotina dos trabalhadores, e que esse perdeu a capacidade de proporcionar bem estar e lazer à população. Apesar disso, eles ressaltaram que o rio se mantém como um marco natural, considerado ainda como cartão postal da cidade pela sua historicidade (Santos; Vital. Informação oral, 2021).

Entre os marcos foram destacados: a Mata do Krambeck, o Museu Mariano Procópio, a Praça Mariano Procópio, o Sport Club Olímpico, a Catedral das Assembléias de Deus, a Prefeitura de Juiz de Fora e a MRS Logística. Os pontos nodais foram identificados na Praça Mariano Procópio, na esquina entre a Avenida Rio Branco e a Avenida Francisco Bernardino e na esquina entre a Avenida Brasil e a Avenida Garibaldi Campinhos. O Rio Paraibuna, além de ser considerado um importante caminho e um marco, também foi considerado como limite natural. Por fim, foram identificados dois setores no recorte de estudo: 
a área da Feira Livre da Avenida Brasil, por ser uma região de comércio regulamentado e padronizada; e a área da Prefeitura de Juiz de Fora e da MRS Logística, por ser considerada como administrativa e empresarial (Santos; Vital. Informação oral, 2021). O mapeamento seguinte (figura 8) sintetiza as informações colhidas pelas entrevistas.

Figura 8: Percepção ambiental pela população local.

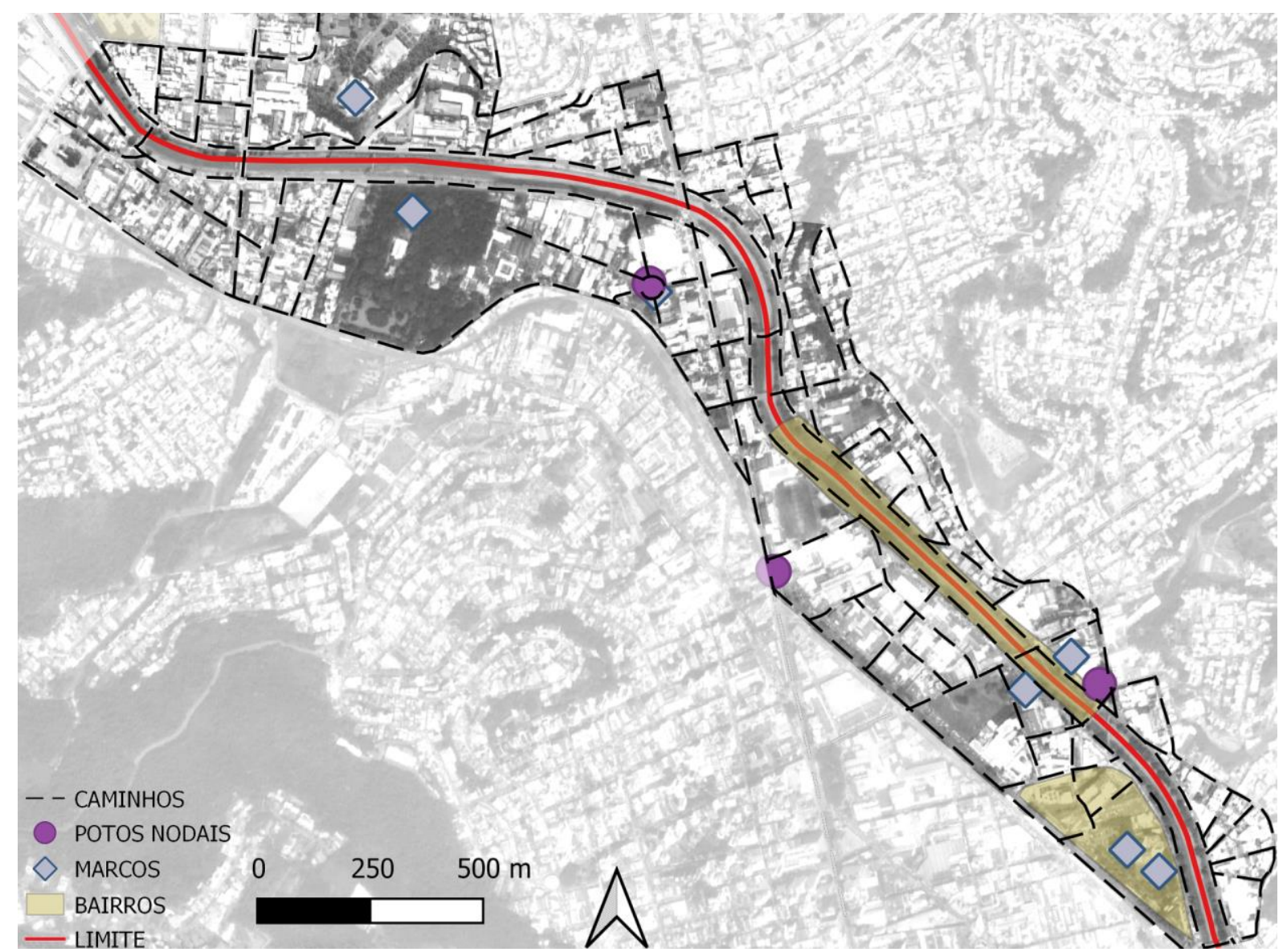

Fonte: QGis, adaptado pela autora (2021).

\subsection{Conexões Ecológicas}

Corredores ecológicos são conexões entre massas florestais que proporcionam deslocamento e abrigo para a fauna e para a flora, favorecendo sua biodiversidade, reprodução e preservação, por facilitar o fluxo genético entre regiões distintas. Também contribui para a cidade e para seus moradores regulando o microclima e possibilitando a criação de parques retilíneos (Seoane, 2010).

De acordo com o estudo da evolução urbana em períodos morfológicos de Juiz de Fora, o Rio Paraibuna denota o surgimento e desenvolvimento inicial da cidade. Ao longo dos períodos e do desenvolvimento industrial, tecnológico e econômico, o rio perdeu sua importância inicial e, consequentemente, foi poluído pelos dejetos da população. As entrevistas com os trabalhadores locais revelaram que, apesar de ser reconhecida sua importância da historicidade da cidade, o rio foi se tornando, ao longo do tempo, um incômodo devido à sua evidente poluição visual e olfativa (Santos; Vital. Informação oral, 2021).

Baseado nas análises do trabalho, é proposta a implementação de um corredor ecológico ao longo das margens do Rio Paraibuna, com reflorestamento baseado em espécies nativas da região, estrategicamente escolhidas como forma de biorremediação da poluição. A vegetação funcionaria, também, como parque linear, proporcionando lazer e diversos serviços 
ecossistêmicos como: regulação da temperatura e da umidade locais; degradação dos poluentes, otimizando o conforto olfativo e visual; valorização estética; entre outros - ilustrado pela Figura 9.

Figura 9: Resultados propostos.

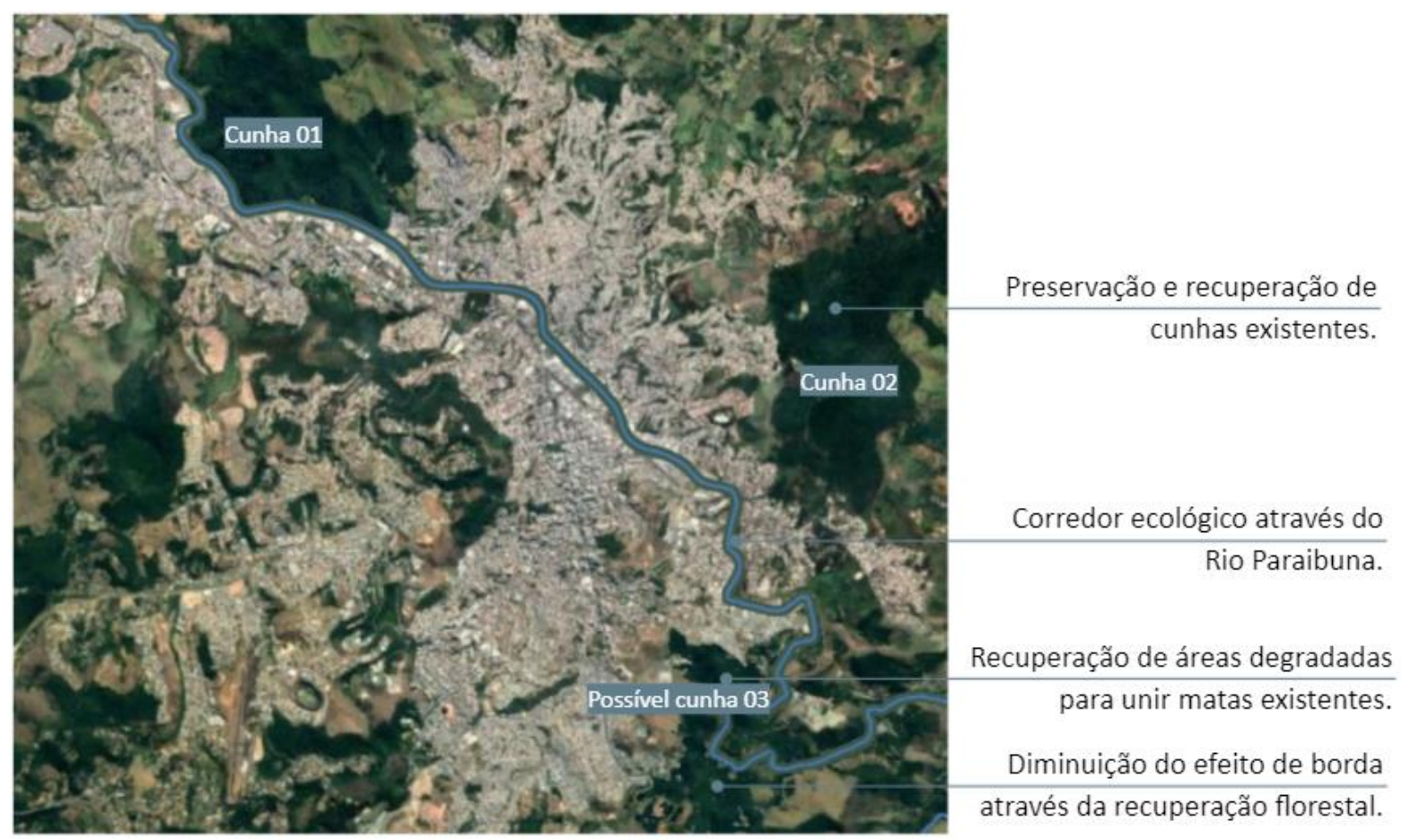

Fonte: QGis, adaptado pela autora (2021).

Além disso, a implantação de parque linear valoriza a importância do trecho no processo urbano de Juiz de Fora, e resgata seu significado perante à população, ampliando a capacidade de historicidade e integrando os elementos naturais às construções de seu entorno. A Figura 10 demonstra o potencial como área de lazer e de exuberante paisagismo nativo. 
Figura 10: Ilustração de parque linear ao longo das margens do Rio Paraibuna.

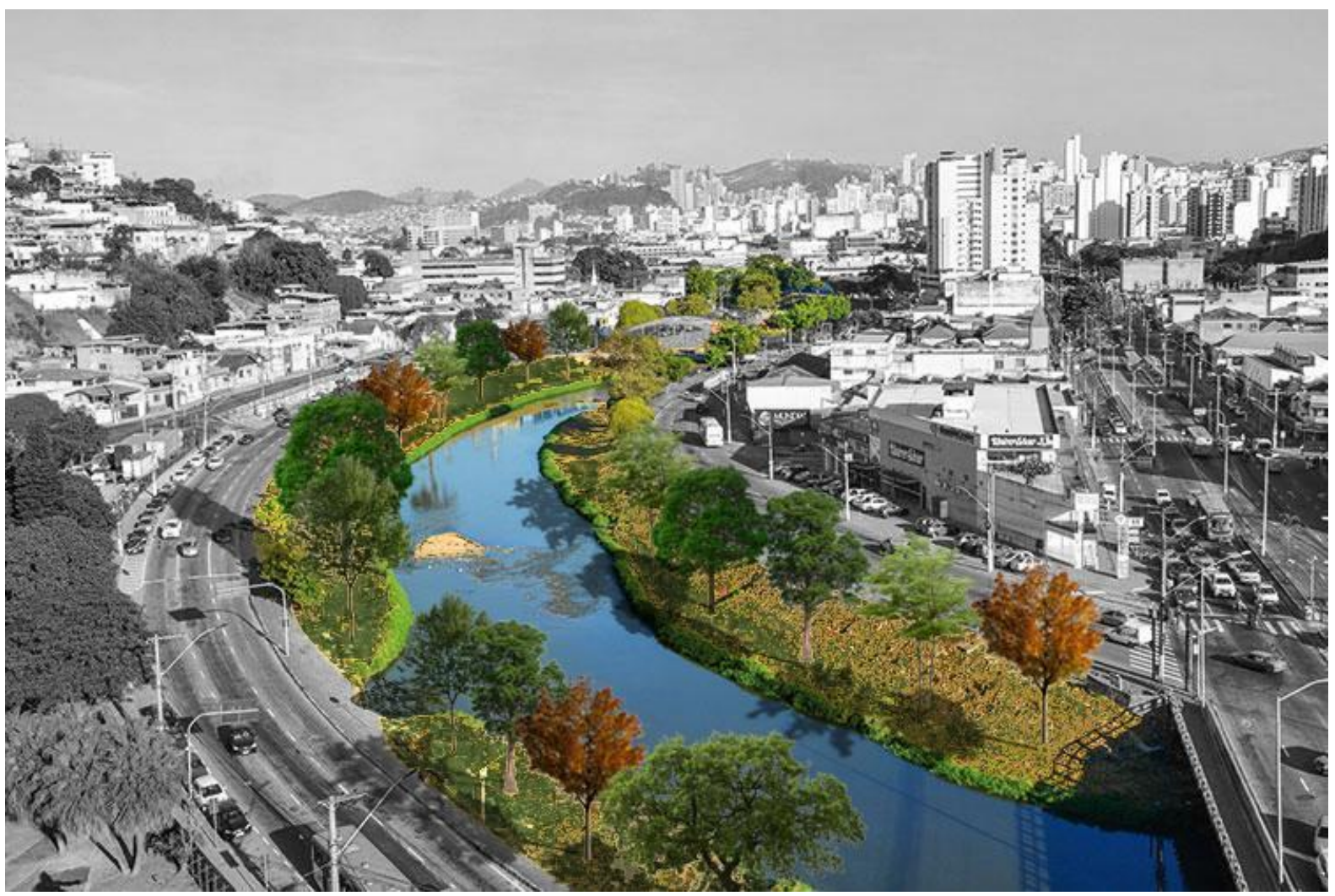

Fonte: Arquivo pessoal (2021).

\section{Considerações Finais}

As informações sobre as características geofísicas da cidade, como bacia hidrográfica e tipo de solo, denotam a facilidade de crescimento arbóreo característica da região de Zona da Mata e Floresta Atlântica. O processo de desenvolvimento urbano do recorte de estudo, por sua vez, demonstra o papel de vetor de surgimento e de desenvolvimento urbano que o rio representou nos primórdios da história de Juiz de Fora: a forma urbana foi determinada pelo trajeto do rio, que guiou as primeiras moradias até o adensamento da região e, posteriormente, de outras áreas da cidade.

Apesar disso, as entrevistas com a população local revelaram o parcial apagamento do significado histórico do rio perante os seus habitantes, devido ao crescente processo de poluição e à negligência perante o rio.

A proposta de corredor ecológico e parque linear nas suas margens atua como valorização da historicidade que o rio representa para a cidade e como forma de lazer à população, proporcionando maior qualidade de vida para os que habitam a região.

Para isso, é importante ressaltar a necessidade de aprofundamento - ao longo da continuação do presente trabalho - no estudo de espécies vegetais adequadas para implementação do parque linear, a fim de proporcionar fitorremediação da poluição do rio e propiciar bem estar aos moradores.

\section{Referências}

Barbosa, Y. A. (2013). O Processo Urbano de Juiz de Fora - MG. Universidade Federal de Juiz de Fora.

Botti, C. A. H. \& Oliveira, M. R. (2004). História de Juiz de Fora. Companhia Mineira de Eletricidade. Companhia Energética de Minas Gerais, Centro de Pesquisas Sociais, UFJF, 19-20.

Cardim, M. E. \& Tunes, G. (2019). Apenas 6,5\% dos rios brasileiros têm boa qualidade da água, aponta estudo. Correio Braziliense. https://www.correiobraziliense.com.br/app/noticia/brasil/2019/03/23/interna-brasil,744836/amp.shtml. 
Research, Society and Development, v. 11, n. 2, e40511225947, 2022

(CC BY 4.0) | ISSN 2525-3409 | DOI: http://dx.doi.org/10.33448/rsd-v11i2.25947

Carvalho, A. C. B. et al., Rocha, G. C. \& Zaidan, R. T. (2019). Zoneamento e análise da classificação dos solos da bacia hidrográfica do Rio Paraibuna a partir do projeto Radam Brasil. Juiz de Fora.

CESAMA (2019). Hidrografia em Juiz de Fora. http://www.cesama.com.br/pesquisa-escolar/hidrografia-em-juiz-de-fora.

Conzen, M. R. G. (1998). Thinking About Urban Form. New York: Papers on Urban Morphology.

Correa, M. L. (2021). Avenida Brasil com 78 Fotografias. Maurício resgatando o passado. Juiz de Fora, s/d. https://mauricioresgatandoopassado.blogspot.com/search/label/Avenida\%20Brasil.

Dilly, R. (2004). Origens de Juiz de Fora. In Juiz de Fora - História, texto e imagem. Juiz de Fora: FUNALFA.

Geraldo, W. M. J. A. (2004). Reestruturação Urbana Pós-fordista de Juiz de Fora. https://docplayer.com.br/8672690-A-reestruturacao-urbana-pos-fordista-dejuiz-de-fora.html.

Gil, A. C. (2008). Métodos e técnicas de pesquisa social. (6a ed.). Atlas.

Lessa, J. (1985). Juiz de Fora e seus Pioneiros: do Caminho Novo à Proclamação. Juiz de Fora: Universidade Federal de Juiz de Fora.

Oliveira, M. R. (2004). Juiz de Fora: Vivendo a Cidade. Juiz de Fora: FUNALFA.

Pereira Costa, S. A. \& Gimmler Netto, M. M. (2015). Fundamentos de Morfologia Urbana. C/Arte.

Prefeitura de Juiz de Fora. (2017). A Cidade. http://pjf.mg.gov.br/cidade/index.php.

Prefeitura de Juiz de Fora. (2014). Plano de Saneamento Básico de Juiz de Fora. https://planodesaneamento.pjf.mg.gov.br/.

Ribeiro, E. L. (2020). História Ilustrada de Juiz de Fora. https://jfhistoria.wordpress.com/tag/caminho-velho/.

Sampieri, R. H., Collado, C. F. \& Lucio, M. P. B. L. (2013). Metodologia de Pesquisa. (5a ed.). Penso.

Santos, M. C. (2021) Informação Oral: Diálogo I (6min17seg).. Pesquisadora: Karla Carvalho de Almeida. Juiz de Fora.

Seoane, C. E. et al Diaz, V., Santos, T. \& Froufe, L. C. (2010). Corredores ecológicos como ferramenta para a desfragmentação de florestas tropicais. https://pfb.cnpf.embrapa.br/pfb/index.php/pfb/article/view/158/114.

Sehling, L. J. (1979). Juiz de Fora - A Companhia União e Indústria e os alemães. Edição da Prefeitura Municipal de Juiz de Fora. Juiz de Fora: FUNALFA.

Tabanez, A. A. J., Viana, V. M. \& Dias, A. S. (1997). Consequências da fragmentação e do efeito de borda sobre a estrutura, diversidade e sustentabilidade de um fragmento de Floresta de Planalto de Piracicaba, SP. Revista Brasileira de Biologia. p.47-60.

Vital, G. (2021). Informação Oral: Diálogo I (14 min 36 seg). Pesquisadora: Karla Carvalho de Almeida. Juiz de Fora. 